\title{
Pattern of Congenital Heart Diseases and Treatment Options in a Bangladeshi Centre: Analysis of 6914 cases from Non-invasive Cardiac Laboratory
}

\author{
Nurun Nahar Fatema \\ Combined Military hospital, Dhaka
}

\begin{abstract}
:
Keywords: $\quad$ Background: Echocardiography is the most sensitive tool to diagnose congenital heart diseases Congenital heart disease, echocardiography, VSD, ASD. efficiently. It can be repeated as many times as required to see the progress, outcome of treatment and complications. Echocardiography laboratory can give a scenario of pattern of congenital heart diseases existing in Bangladesh as well as natural history of the cases and treatment options offered.

Methods: It is a retrospective review of database of echocardiography patient from pediatric noninvasive laboratory of a cardiac hospital from January 2012 to December 2012.

Results: Out of 6914 cases $55.73 \%$ were male and $44.27 \%$ female. Neonates include $8.48 \%$, 36.62\% Down Syndrome were infant, $34.02 \%$ were under 5 years, $17.97 \%$ were children and adolescents and $2.96 \%$ were adults. Normal Echocardiography finding was found in $17.28 \%$ cases. Ventricular septal defect (VSD) was found in 18.60\% cases, Atrial septal defects (ASD) in $15.41 \%$ cases, Patent ductus arteriosus (PDA) in $8.59 \%$ cases, Atrioventricular septal defect (AVSD) in 1.97\% cases, Tetralogy of Fallot (TOF) in 4.79\% cases and Transposition of great arteries (TGA) in $2.26 \%$ cases. Down syndrome was the commonest chromosomal abnormality seen in $2.4 \%$ cases.
\end{abstract}

Conclusion: This study shows that VSD is the commonest congenital heart lesions in our country followed by ASD. Down syndrome was the commonest chromosomal abnormality seen in $2.4 \%$ cases.

(Cardiovasc. j. 2017; 9(2): 97-105)

\section{Introduction:}

The incidence of congenital heart disease is 8 per thousand live births. In a study conducted in Bangladesh showed incidence up to 25/1000 live birth. ${ }^{1,2}$ This wide variation was due to inclusion of only newborn in that study. Echocardiography was performed on all symptomatic and suspected newborn as well as on all high risk babies who had possibility of having congenital heart disease (CHD) ${ }^{2}$ The incidence of CHD in abortous and still born is much higher in other studies. ${ }^{3}$ According to New England regional infant cardiac program, $50 \%$ of all congenital heart problem could be detected by $1^{\text {st }}$ week of life. ${ }^{4}$ VSD is the commonest cardiac malformation found in most of the study. ${ }^{5}$

Echocardiography is the most sensitive, specific and cost effective means to diagnose congenital heart disease safely and correctly. It is a painless investigation without any hazard of radiation and therefore can be repeated as often as required to follow changes in the cardiac condition as well as to assess result of surgery and intervention. It can guide surgeons and interventional cardiologists per operatively. Almost all complex heart disease can be diagnosed by echocardiography. Cardiac catheterization for diagnostic purpose is now not advised in sick newborn and infants. ${ }^{6}$ So echocardiography laboratory is the best place to get data about all kind of patient with congenital heart diseases which includes newly diagnosed cases, cases in follow up, post surgery or post interventional cases.

To the knowledge of the author, no study has been conducted yet from the noninvasive laboratory and

Address of correspondence: Prof. Nurun Nahar Fatema, Combined Military hospital, Dhaka, Bangladesh. email- colfatema@hotmail.com 
outpatient department to see the pattern of disease of large scale patient in Bangladesh and its outcome. This study will help to see the specific pattern and characteristics of patient in Bangladeshi children. Author will try to address specific characteristics of some of the common diseases.

\section{Methods:}

This is a retrospective hospital based study from an open access Echocardiography laboratory of a tertiary care cardiac center of Bangladesh from January to December 2012. All 6914 cases had Echocardiography from non invasive laboratory. All the patients were also seen in outpatient clinic and physical examination, chest x-ray and ECG were analyzed. Patients were referred from almost every district and remote areas of Bangladesh and they may represent whole country scenario. All normal patients were discharged and congenital heart disease cases had given follow up at 01 months to 06 months interval. All chromosomal anomalies and syndromes were diagnosed and recorded. Management plan were designed for all cases. Some of the cases were postoperative or post interventional case and were kept in follow up. All patients who required interventions were performed in Catheterization Laboratory of Combined Military Hospital Dhaka. Patients who required surgery were referred to surgeons of home and abroad after complete work up. Complicated, cyanotic heart disease cases and cases refused by local surgeons were referred to neighboring countries. Some patients were kept on follow up to see progress of disease or to plan intervention/ Surgery in later date. Records of all the patients from Echocardiography lab was preserved in database.

\section{Results:}

Five hundred eighty six (8.48\%) cases were below one month age group. Two thousand five hundred thirty two cases $(36.62 \%)$ were in one month to one year age group, 2352(34.01\%) cases were in more than one year to 5 years age group, 1239 cases $(17.92 \%)$ were in more than 5 years to 18 years age group and 205 (2.97\%) cases were in more than 18 years age group (Fig I). Total 3853 (55.73\%) cases were male was 3061 (44.27\%) cases were female (Fig II).
Total 5719 (82.72\%) cases had positive echo finding for congenital heart disease and 1195 (17.28\%) cases had normal cardiac anatomy (Fig III).

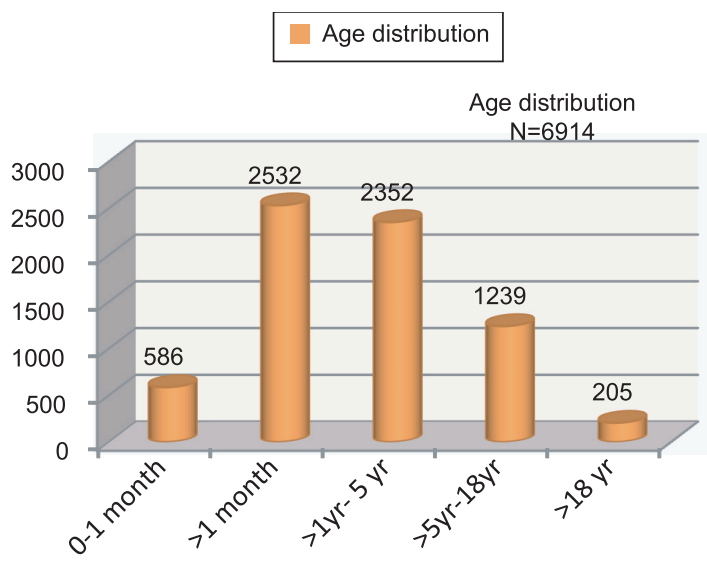

Fig.-1: Age distribution of study population.

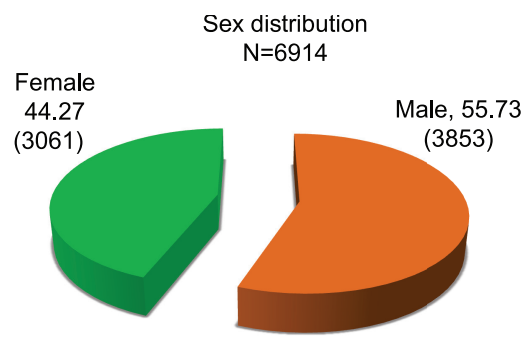

Fig.-2: Sex distribution of study population.

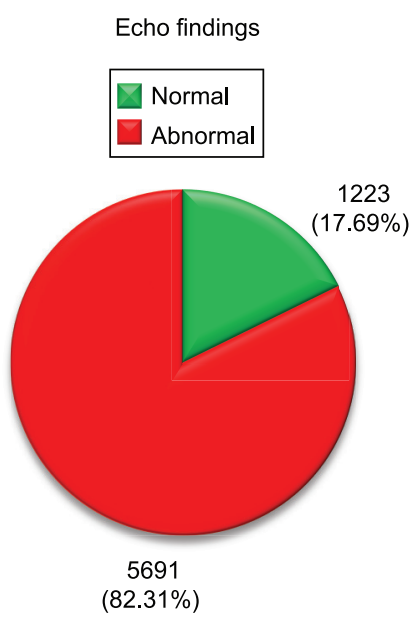

Fig.-3: Distribution of abnormal echocardiography findings in study population $(n=6914)$. 
Table-I

Disease pattern of study cases $(n=6914)$.

\begin{tabular}{|c|c|c|}
\hline A. Cyanotic Congenital Heart disease & Number & Percentage \\
\hline Ventricular septal Defect( VSD) & 1286 & 18.60 \\
\hline Atrial septal Defects (ASD) & 1066 & 15.41 \\
\hline Patent ductus arteriosus (PDA) & 594 & 8.59 \\
\hline ASD,VSD, and PDA & 482 & 6.97 \\
\hline Patent foramen ovale (PFO) & 265 & 3.83 \\
\hline Pulmonary stenosis (PS) & 178 & 2.57 \\
\hline Atrioventricular Septal defect (AVSD) & 136 & 1.97 \\
\hline Aortic Stenosis (AS) & 108 & 1.56 \\
\hline Branch pulmonary artery stenosis & 65 & 0.94 \\
\hline Coarctation of Aorta COA & 60 & 0.87 \\
\hline Dilated cardiomyopathy DCM & 56 & 0.81 \\
\hline Mitral valve prolapsed & 42 & 0.61 \\
\hline Idiopathic pulmonary hypertension (IPAH) & 31 & 0.45 \\
\hline Hypertrophic cardiomyopathy (HCM) & 23 & 0.33 \\
\hline Restrictive cardiomyopathy & 11 & 0.07 \\
\hline $\begin{array}{l}\text { Anomalous origin of Left coronary artery from pulmonary } \\
\text { artery(ALCAPA) }\end{array}$ & 6 & 0.09 \\
\hline Mitral stenosis & 6 & 0.04 \\
\hline $\begin{array}{l}\text { Others (AR, MR, TR, PR, Thrombus, vegetation, Tumor's, } \\
\text { aneurysms, carditis etc.) }\end{array}$ & 389 & 5.19 \\
\hline \multicolumn{3}{|l|}{ B. Cyanotic Congenital Heart disease } \\
\hline Tetralogy of Fallot (TOF) & 331 & 4.79 \\
\hline Trans position of great Arteries (TGA) & 156 & 2.26 \\
\hline Pulmonary Atresia & 108 & 1.56 \\
\hline Double out let right ventricle (DORV) & 94 & 1.36 \\
\hline Persistent pulmonary hypertension newborn (PPHN) & 73 & 1.06 \\
\hline Total anomalous pulmonary venous drainage (TAPVD) & 66 & 0.95 \\
\hline Tricuspid atresia & 62 & 0.89 \\
\hline Double Inlet left ventricular (DILV) & 49 & 0.71 \\
\hline Complex congenital heart disease & 32 & 0.46 \\
\hline Truncus Arteriosus & 27 & 0.39 \\
\hline Persistent fetal circulation (PFC) & 16 & 0.23 \\
\hline Ebstein anomaly & 10 & 0.14 \\
\hline Mitral Atresia & 09 & 0.13 \\
\hline Aorto pulmonary window (AP Window) & 8 & 0.12 \\
\hline \multicolumn{3}{|l|}{ C. Other finding } \\
\hline Normal Echo & 1223 & 17.69 \\
\hline Pericardial effusion & 66 & 0.99 \\
\hline
\end{tabular}

Table I showed the pattern of disease in study population. VSD was found in 1286 (18.6\%) cases, ASD was found in 1066 (15.42\%) case, PDA found in 594
(8.59\%) cases, combination of ASD, VSD, PDA found in $482(6.97 \%)$ cases. TOF found in $331(4.79 \%)$ cases, DORV in 94(1.36) cases, PFO in 265 (3.83\%) cases. 
Table-II

Congenital heart disease with different syndromes $(n=6914)$.

\begin{tabular}{lcc}
\hline Name of syndrome & Number & Percentage \\
\hline Down syndrome & 166 & 2.4 \\
Congenital Rubella & 68 & 0.98 \\
syndrome (CRS) & & \\
Noonan's syndrome & 20 & 0.29 \\
Williams Beuren syndrome & 12 & 0.17 \\
Turners syndrome & 5 & 0.07 \\
GolderHar syndrome & 4 & 0.06 \\
Edward syndrome & 2 & 0.29 \\
Others & 4 & 0.06 \\
\hline
\end{tabular}

Note: Others include DiGeorge syndrome, Patau syndrome, Marfans syndrome, Pierre Robin syndrome.

Table II showed different syndromes associated with the congenital heart disease. Down syndrome was present in 166(2.4\%) cases, congenital Rubella syndrome in $68(0.98 \%)$ cases, Noonan's syndrome in $20(0.29 \%)$ cases, Williams syndrome in $12(0.17 \%)$ cases and Turners syndrome in $05(0.07 \%)$ cases.

\section{Table-III}

Different therapeutic interventions performed in study population $(n=6914)$.

\begin{tabular}{lc}
\hline Name of intervention & Number \\
\hline PDA device closure & 296 \\
ASD device closure & 206 \\
VSD device closure & 28 \\
Pulmonary Balloon valvoplasty & 23 \\
Balloon atrial septostomy & 11 \\
Aortic Balloon valvoplasty & 9 \\
Balloon coarctoplasty & 8 \\
PDA stenting & 8 \\
RVOT stenting and stenting & $07(5+2)$ \\
from VSD to pulmonary artery & \\
CoA stenting & 02 \\
Pulmonary valve Implantation & 01 \\
with Melody & \\
Total intervention & 599 \\
\hline
\end{tabular}

Table III showed types of interventions in study cases. ASD device closure was done in 206(2.89\%) cases, PDA device closure in 296(4.28\%) cases, VSD device closure in $28(0.40 \%)$ cases, Pulmonary Balloon valvoplasty in 23(0.34\%) cases, Balloon atrial septostomy in $11(0.16 \%)$ cases, Aortic Balloon valvoplasty 09(0.13\%) cases, Coarctoplasty in $08(0.12 \%)$ cases and PDA stenting in $08(0.12 \%)$ cases. Coarctation (CoA) stenting was performed in $02(0.02 \%)$ cases. Pulmonary valve implantation (PPVI) was performed in 01(0.01\%) case which was the first ever cases of PPVI in south Asia. Right ventricular outflow tract (RVOT) stenting was performed in 7(0.11) cases.

Table-IV

Different types of surgery performed in study population $(n=6914)$.

\begin{tabular}{lc}
\hline Name of surgery & Number \\
\hline VSD closure & 173 \\
ASD closure & 107 \\
TOF repair & 74 \\
Bidirectional Glenn shunt for & 58 \\
SV physiology/anatomy & \\
AV canal repair & 35 \\
Rerouting of TAPVC & 22 \\
Blalock Taussig shunt & 21 \\
Coarctation repair & 19 \\
Arterial switch operation & 14 \\
for TGA (ASD) & \\
Mitral valve repair & 6 \\
Truncus repair & 4 \\
A-P window repair & 3 \\
PDA ligation & 3 \\
Tricuspid valve repair for & 3 \\
Ebstein Anomaly & \\
Pulmonary artery banding for (DILV) & 3 \\
Rastelli operation & 2 \\
Aortic valve repair & 1 \\
Total surgery & 548 \\
\hline
\end{tabular}

Table IV showed different types of surgery in study cases. Total 173(2.5\%) cases had VSD closure, 107(1.5\%) had ASD repair, 74 (1.07\%) cases had TOF repair, 35(0.50\%) cases had Atrio ventricular canal (A-V canal )repair, 58(0.83\%) cases had bidirectional Glenn (BDG) operation for single ventricle physiology, 14(0.20\%) had Arterial switch operation (ASO) for transposition of great arteries (D-TGA), $22(0.32 \%)$ had rerouting of total anomalous pulmonary venous drainage (TAPVC),21(.031\%) had Blalock Taussig (BT) shunt and 19(0.27\%) had Coarctation repair. 


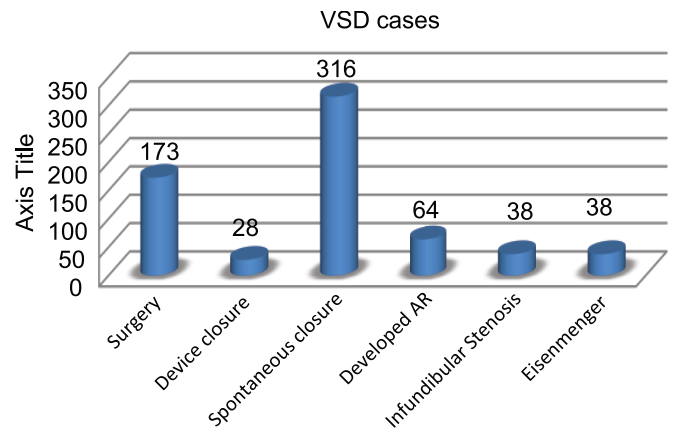

Fig.-4: Distribution of VSD cases $(n=1286)$.

Fig V showed distribution of VSD (1286) cases. One hundred seventy three (13.45\%) cases had VSD closure, 28(0.40\%) cases had VSD device closure, $316(24.57 \%)$ cases had spontaneous closure, 64 (05\%) cases developed aortic regurgitation (AR).

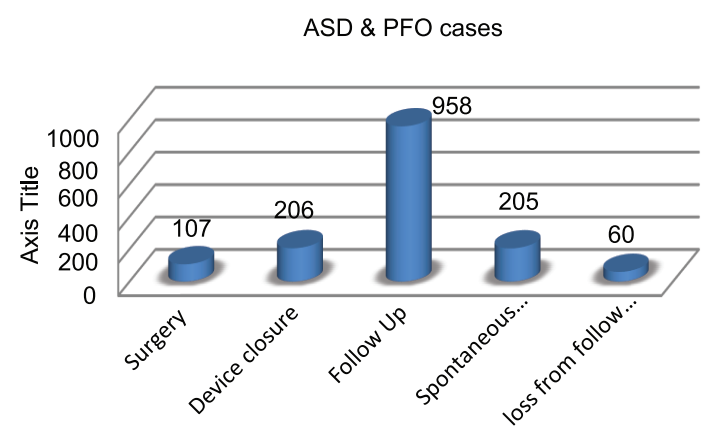

Fig.-5: Distribution of $A S D$ and $P F O$ cases ( $n=$ 1331).

Fig VI showed Distribution of ASD and PFO cases. Total 1331(100\%) cases had various type of ASD and PFO. Surgical closure was performed in 107(8.04\%) cases. Device closure was performed in $206(15.48 \%)$ cases. Two hundred five (15.40\%) cases had spontaneous closure during follow up. Total 958 (71.97\%) cases were in follow up to see the progress of disease and to design management

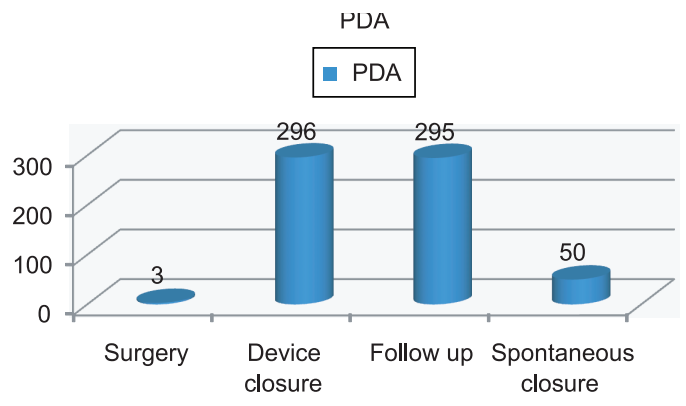

Fig.-6: Distribution of PDA cases $(n=594)$. plan. In this study 60 (4.5\%) cases of ASD and PFO were lost from follow up.

Fig VII showed Distribution of PDA cases. Out of 594 cases, 296(49.82\%) cases had device closure. Three cases had (0.50\%) surgical closure. Out of 296 device closed cases 220 (37.03\%) had classical PDA and 76(12.99\%) had Large tubular PDA. Fifty (8.42\%) cases of PDA closed spontaneously. In adult cases with PDA, twisting of PDA observed in 7 cases and snare assisted device closure was performed like VSD device closure.

Table-V: Follow up of cases in next year $(n=6914)$.

\begin{tabular}{lcc}
\hline Follow up & No & Percentage \\
\hline Reported & 6444 & 93.20 \\
Not reported & 470 & 6.80 \\
Spontaneous cure/ cured & 678 & 9.80 \\
with medical treatment & & \\
\hline
\end{tabular}

Table $\mathrm{V}$ showed follow up of cases in next year. Total 6444 (93.20\%) cases reported and 470(6.80\%) had not reported or lost form follow up. Six hundred and seventy eight (9.80\%) cases had spontaneous cure of ASD secundum, VSD, PDA and PFO.

\section{Discussion:}

Term congenital heart disease is defined as structural and functional problems of the heart which are present at birth. It is the most common type of birth defect. Prevalence of CHD worldwide was ranged between1-150 per 1000 live births. ${ }^{6}$ The CHD are considered as multifactorial defects, majority do not segregate in mendalian ratio, although familial aggregation present. ${ }^{7}$ Most of the known cases of $\mathrm{CHD}$ are sporadic genetic variations, point mutations, duplication or deletion. ${ }^{8}$ A large number of chromosomal abnormalities such as trisomy 21,18 , and 13 are associated with CHD in 5-8\% cases. 9,10

Because of improvement in health care system, more patients are surviving and entering into adulthood. At the same time diagnosis in neonatal period also increased because of awareness among neonatologist about the disease. Studies on prevalence, age, sex distribution and proportion of adults and children patient were analyzed in many studies. ${ }^{11,12}$ The prevalence was found as 4 per 1000 for all CHD, female accounts for $57 \%$ of adult cases and 0.38 per 1000 cases had severe 
CHD. The median age for severe CHD was II years. Male outnumbered female (55.73\%) in this study. In this study most of the patients were in $>1$ month to 1 year age group (36.62\%). Possibly this is because of existence of many newborn and children in the study and inclusion of all kind of diseases. CHD prevalence is usually high in female adults and with ASD, VSD, PDA and AV canal Defect. Male predominance is observed in children with coarctation of aorta and transposition complex. ${ }^{13}$

A large number of patients (17.96\%) in the study group had normal echocardiographic findings. They were referred on the basis of suspicion or for the screening purpose.

Analysis of disease pattern in study group showed that VSD is the commonest type of CHD followed by ASD and PDA. VSD was found as commonest CHD in many studies. ${ }^{11}$ Incidence of VSD is much higher if all newborn are sent for Echocardiography, lower if newborn with murmur are examined and still lower if Echo examination is delayed up to one year when $85-90 \%$ of small defects closed spontaneously. ${ }^{12-15}$ Tetralogy of Fallot was the commonest cyanotic CHD. Now a days Echocardiography examinations are so accurate that few misdiagnoses are possible. So, Echocardiographic classification of diseases and inclusion of problems in the study cases can be considered as true representation of a population group.

Among genetic \& chromosomal defect, Down syndrome was commonest in our series. Down syndrome was commonest syndrome in other studies also. ${ }^{16,17}$

Among the patients who were treated with interventional technique, PDA device closure was commonest; ASD device closure was $2^{\text {nd }}$ highest. Rapid growth of transcatheter device closure has now largely replaced surgical closure of secundum ASDs in most centres. ${ }^{18}$ There has been no large comparison of surgery with transcatheter closure of ASD as design of such study is problematic because, given a choice between surgery and device closure, parents and patients often prefer the later method. ${ }^{18}$ In a follow up of Dutch group, no cardiovascular mortality was found, however (6\%) patient had supra ventricular tachycardia in surgery group. ${ }^{19}$
VSD closure was the commonest surgical procedure performed in this series which is similar to other studies. ${ }^{5}$ It was followed by ASD closure, TOF repair, bidirectional Glenn shunt, AV canal repair etc.

Out of 1286 cases of VSDs, 173 cases had surgical closure and 28 cases had device closure. All kind of VSDs were referred for surgical closure but only perimembranous VSD cases were accepted for device closure. A comparative study of surgical versus device closure of perimembranous VSD showed excellent midterm outcome. ${ }^{20}$ Device closure cases had less myocardial injury, fast recovery, short hospital stay and lower medical expense. In our series no complications noticed in device closure group. Residual VSD, conduction defect with pacemaker implantation and persistence of pulmonary hypertension were observed in four postsurgical cases.

In this series, out of 1331 ASD and PFO cases, surgical closure was performed in 107 cases which includes all type of ASDs, only ASD secundum type were suitable for device closure. Spontaneous closure was observed in $15.40 \%$ cases.

PDA device closure was performed in $49.82 \%$ of all 594 cases of PDA in this series. Only $3(0.05 \%)$ cases had surgical closure. In our series large tubular PDAs were closed with devices and few newborn with heart failure also had device closure with successful outcome. A Meta analysis showed no significant cost advantage in primary success rate, total complications or rate of blood transfusion in device and surgery group. ${ }^{21}$ In our series device group had almost no complications and success rate was $100 \%$ in attempted patient.

Records of follow up of these case in 2013 was analyzed and showed $93.20 \%$ patient attended follow up, $6.80 \%$ patient were lost from follow up and $9.80 \%$ of cases had spontaneous cure or get cured after treatment. Spontaneously cured cases were PFO, ASD, VSD, and PDA and cured after treatment were persistent pulmonary hypertension of newborn (PPHN), pericardial effusion (PE), dilated cardiomyopathy (DCM) etc. PPHN were treated by special protocol designed by the author and $99 \%$ of patient cured with 72 hours short course of treatment. ${ }^{22}$

We have noticed some individual pattern in Bangladeshi children in some specific CHDs which are highlighted bellow. 
Ventricular Septal defects (VSD): In this study 1286 (18.60\%) cases were VSD. Isolated VSDs are so far found as most common CHD in studies from many centers also. Special features which we observed in our cases are:

1. Get smaller and closed spontaneously in $23.32 \%$ cases in young children. Spontaneous closure after 3 years of age is rare.

2. Get larger in few cases.

3. Large perimembranous and muscular VSDs were not closed.

4. Large perimembranous, muscular and outlet VSD developed Eisenmenger syndrome in 3\% cases.

5. Developed infundibular stenosis in $3 \%$ cases.

6. Small VSD has big shunt in some (1\%) cases, developed aortic regurgitation (AR) in 5\% cases.

Atrial septal defect (ASD): ASD of secundum type give many problems of classification and diagnosis. Many patients have PFO and inclusion of these with ASD increased the incidence. More over ASDs more than $5 \mathrm{~mm}$ in size also close spontaneously and timing of Echo study thus influence the incidence. Incidence in childhood also underestimates adults who escaped early diagnosis for lack of symptoms and physical findings. Special feature in our children are:

1. ASDs got smaller in size and closed spontaneously in majority of ASDs (secundum) which are small or moderate in size.

2. Became larger with age in some cases.

3. Device closure success rate is high in children than adults. Rim of children are more supportive than adult and better waist appear in children with balloon sizing. Eisenmenger syndrome is less common in ASD secundum cases thus allow many adult (Late diagnosis) cases to be cured by treatment.

Patent ductus arteriosus (PDA): Frequency of PDA was $8.59 \%$ in this study. Incidence of PDA varies with the age at the time of study and gestational age of the patient. Inclusion of preterm infant in the study inflates the incidence of PDA. In term infant normal ductus remain patent for some time and functional closure precedes obliteration. Studies based on Echocardiography showed PDA is always closed by four to seven days of life in term infants. In Bangladeshi children special feature are:

1. Most of the PDA in term and preterm babies (80\%) closed by seven days of life.

2. Large tubular PDA is common in Down syndrome, Rubella syndrome and in some newborn babies and children.

3. Tubular PDA had rapid development of Eisenmenger syndrome.

4. Significant cases under 3 years had large tubular PDA. These tubular PDA are closed with devices. In seven cases PDA device closure was performed in adult by snare assisted technique as PDA was twisted.

Tetralogy of Fallot: In this study 331 (4.79\%) cases had TOF. TOF is the commonest cyanotic CHD in Bangladesh. Total correction with trans-annular patch developed pulmonary regurgitation of various degrees in most of the cases. Valve replacement, redo surgery and surgery with $R V$ to PA conduit were performed in some study cases. Conduit change was required in 6 cases and pulmonary valve replacement with Melody was done in 1 case. Untreated TOF has cerebral abscess and stroke in some cases. Cyanotic spell was found common in 6 month to 2 years of age. Four cases developed hemi paresis from acute stroke syndrome.

Transposition of great arteries: TGA with ASD secundum and PDA is common than TGA with VSD in Bangladeshi Children. Taussig Bing Anomaly was seen in some cases of double outlet right ventricle. Newborn babies with TGA do very well after septostomy. Complications after arterial switch operation were minimum. Only two cases developed severe right ventricular out flow tract obstruction.

Pulmonary Atresia : In this study 108 (1.56\%) patient had pulmonary atresia, most of them had VSD. Pulmonary atresia with intact ventricular septum was less common. Major Aortopulmonary collaterals (MAPCA) were a common association with VSD. PDA was vertical, tortuous in most of the cases of PA and VSD cases and was difficult for stenting. In pulmonary Atresia intact septum cases, PDA was classical and stenting was 
successful in all of these cases. Balloon atrial septostomy was done in few cases with PFO to ensure flow of blood to left heart through ASD.

Single ventricle of LV type: Other associations were found in majority of the study cases. Those with restrictive pulmonary blood flow usually remain stable for long time. Those with TGA or with nonrestrictive pulmonary flow developed heart failure. Double inlet left ventricle (0.44\%) was commonest of these group in our study.

Tricuspid Atresia: Tricuspid atresia was found in $0.89 \%$ cases. Some of the cases had TGA \& some of the cases had associated PS or pulmonary atresia. All the cases were planned for bidirectional Glenn shunt. Those with increased pulmonary artery blood flow; Pulmonary artery banding was advised. Two cases with restrictive VSD had stenting from VSD to pulmonary artery.

Most of the patients who were referred for echocardiography had one or more echocardiography performed from other centers. Many reports especially from remote places were wrong. Even reports from good centers were incorrect on many occasions. Diseases which were mistaken commonly are:

1. Coarctation of aorta in infants.

2. Persistent pulmonary hypertension of newborn.

3. Persistent fetal circulation.

4. Large VSD with reverse shunt.

5. Comments on ventriculoarterial relationship in complex cases.

6. Differentiation of truncus arteriosus and pulmonary atresia.

7. Anomalous origin of left coronary artery from pulmonary artery (ALCAPA).

8. Coronary artery fistula.

9. Atretic condition of valves.

10. Aortico left ventricular tunnel (ALVT).

11. Ruptured sinus of valsalva etc.

Pediatric cardiology subspecialty is a relatively new subject in Bangladesh (started in 1998). Many cardiac hospitals have no pediatric cardiologist and service available only in few centers of capital city
Dhaka. So wrong diagnosis, wrong management plan, delay in getting treatment, non availability of surgery for complex congenital heart diseases are the challenges currently we are facing.

\section{Conclusion:}

Our study was an Echocardiography based study where cases were referred to pediatric cardiologist of a tertiary care hospital. VSD was the commonest congenital heart disease followed by ASD and PDA. TOF was the commonest cyanotic CHD. Down syndrome was the commonest syndrome associated with CHD. Amongst intervention PDA device closure was highest in this series. VSD closure was the highest surgical procedure. Spontaneous cure of CHD was also observed in significant number of cases.

\section{Conflict of Interest - None.}

\section{References:}

1. Jeffery J, Pomerane MPH, Joan Richardson MD. A Neonatology for the clinician. Norwalk (Connecticut): Appleton \& Lange, 1993: 122p.

2. Thomas R Kimbol, Erik C Michelfelder. Echocardiography: Basic principles and imaging. In: Hugh D Allen, David J Driscoll, Robert E Shaddy, Timothy F feltes, editors.Moss and Adam,s Heart disease in Infant, Children\&Adolescents. $8^{\text {th }}$ ed. Philladelphia: Williams\& Wilkins. 2013; 134-203p.

3. Rebecaca Snider, Gerelda A, Serwer MD, Samuel B. Ritter MD. 1997. Echocardiography in Paediatric Heart Disease. $2^{\text {nd }}$ ed. Baltimore: Mosby Year book inc. 345p.

4. Williams RG, Bireman FZ, Sanders SP. Echocardiographic diagnosis of cardiac malfunctions. Boston: Littlebrown. 1998; 455p

5. Nurun Nahar Fatema. 2011. Congenital cardiac interventions and research work in Bangladesh. Dhaka: Asian color prints. 26-30 .

6. Ramegowda S, Ramachandra NB. An understanding the genetic basis of congenital heart disease. Indian $J$ Hum Genet 2005;11(1):14-23.

7. Oyen N, Poulsen G, Boyd HA, Wohlfahrt. Recurrence of congenital heart defects in families. Circulation 2009; 28;120(4):295-301.

8. Prasad C, Chudley AE. Genetics and cardiac anomalies: The heart of the matter. Indian J Pediatr 2002 Apr;69(4):321-332.

9. Nisli K, Oner N, Candan S, Kayserili H, et al. Congenital heart disease in children with Down's syndrome: Turkish experience of 13 years. Acta Cardiol 2008 Oct; 63(5): 585-589. 
10. Hoe TS, Chan KC, Boo NY. Cardiovascular malformations in Malaysian neonates with Down's syndrome. Singapore Med J 1990 Oct;31(5):474-476.

11. Warnes CA, Liberthson R, Danielson GK, Dore A, Harris L, Hoffman JI et al. Task force1: the changing profile of congenital heart disease in adult life. $\mathrm{J} \mathrm{Am} \mathrm{Col} \mathrm{Cardiol}$ 2001; 37: 1170-1175.

12. Hoffman JI, Kaplan S. The Incidence of congenital heart disease. J Am Col Cardiol 2002; 39: 1890-1900.

13. Hoffman JI, Kaplan S, Liberthson RR. Prevalence of congenital heart disease. Am Heart J 2004; 147: 425439 .

14. S Hinaishi, Y Agata, M Nowatari. Incidence and natural course of trabecular ventricular septal defect: Two dimentional Echocardiography and colour Doppler flow Imaging study. J Pediatr 1992; 120: 409-415.

15. Kidd SA, Lancaster PAL, McCrdie RM. The Incidence of congenital heart defects in the first year of life. $J$ Paediatr Child Health 1993; 29: 344-349.

16. Johnson MC, Hing A, Wood MK, Watson MS. Chromosome abnormalities in congenital heart disease. Am J Med Genet 1997 Jun 13;70(3):292-298.
17. Christianson AL. Down syndrome in sub-Saharan Africa. J Med Genet 1996 Feb;33(2):89-92.

18. Spence MS, Qureshi SA. Complications of transcatheter Closure of atrial septaldefects. Heart 2005; 91 (12): 15121514.

19. Konstantinides S, Geibel A, Olschewk M. A comparison of surgical and Medical therapy for atrial septal defect in adults. $N$ Engl $J$ Med 1995; 333: 469- 473.

20. Yang J, Yang L, Yu S, Liu J, Zur J, Chen W, et al. Transcatheter versus surgical closure of perimembranous ventricular septal Defects In Children: a randomizaed control trial. J Am Col Cardiol 2014; 63(12): 1159- 1168.

21. Wang K, Pan X, Tang Q, Pang Y. Catheterization therapy versus surgical closure In pediatric patients with patient ductus arteriosus: A Meta-analysis. Clincardiol 2014; 37(3): 188-194.

22. Fatema NN, Khan MR, Kabir MS. Persistent Pulmonary hypertension of the newborn ; Analysis of 93 cases over one year . Bangladesh Journal of Cardiology 2012; 4(1): 45-49. 